\title{
COVID-19, vacunas y piel
}

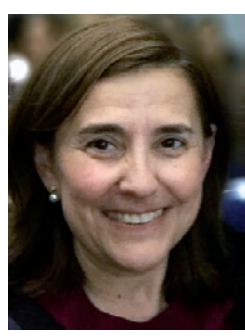

M. a Pilar Arrazola Martínez

Jefe de Servicio de Medicina Preventiva. Hospital Universitario 12 de Octubre. Madrid.
La vacunación es la estrategia más efectiva y eficiente de prevención primaria. Su contribución ha sido fundamental para disminuir la incidencia, morbilidad y mortalidad de las enfermedades infecciosas.

La relación entre las vacunas y la piel se inicia con la historia misma de la vacunación. En 1796, Edward Jenner descubrió la vacuna contra la viruela, una enfermedad muy contagiosa que se manifestaba con síntomas generales graves y un exantema pustuloso característico, que dejaba cicatrices residuales graves en la cara y las extremidades ${ }^{1}$.

En los inicios de la vacunación frente a la viruela en España, encontramos dos nombres que se nos han hecho familiares en esta pandemia. El Dr. Balmis fue el director de la Real Expedición Filantrópica de la Vacuna, organizada por el rey Carlos IV en 1803 para extender la vacunación por todos los dominios españoles en Ultramar y conseguir así allí la eliminación de la viruela. Isabel Zendal era la Rectora de la Casa de Expósitos de La Coruña y fue la responsable del cuidado de los niños que participaron en esta expedición; en 1950, la Organización Mundial de la Salud (OMS) la reconoció como la primera enfermera de la historia en misión internacional $^{1}$.

Desde entonces y hasta la actualidad, muchas de las vacunas utilizadas rutinariamente en niños y adultos se dirigen frente a infecciones en las que los signos y síntomas cutáneo-mucosos son una de sus características más identificativas. Es el caso, por ejemplo, de la difteria (forma cutánea), el sarampión, la rubeola, la varicela, el herpes zóster, la enfermedad meningocócica y la infección por el virus del papiloma humano.

Las vacunas son una de las historias de éxito de la medicina moderna. La pandemia de la enfermedad por coronavirus (COVID-19; por el acrónimo del inglés, coronavirus disease 2019), que está causando enormes costes humanos y económicos en España y en el mundo, ha evidenciado, una vez más, su gran valor. La vacunación frente al coronavirus de tipo 2 causante del síndrome respiratorio agudo severo (SARS-CoV-2; del inglés, severe acute respiratory syndrome coronavirus 2) se plantea como la única alternativa, en el momento actual, para su control. Su objetivo es prevenir la enfermedad y disminuir su gravedad y mortalidad, además de reducir el impacto de la pandemia sobre el sistema asistencial y la economía, protegiendo especialmente a aquellos grupos con mayor vulnerabilidad ${ }^{2}$.

El 31 de diciembre de 2019, la Comisión Municipal de Salud y Sanidad de Wuhan (provincia de Hubei, China) informó sobre un grupo de 27 casos de neumonía de etiología desconocida, con una exposición común a un mercado mayorista de marisco, pescado y animales vivos en esa ciudad. El 9 de enero de 2020, las 
autoridades chinas anunciaron la identificación como agente causante del brote de un nuevo tipo de virus de la familia Coronaviridae, que posteriormente ha sido denominado SARS-CoV-2, y liberaron su secuencia genética el 10 de enero. El día 11 de marzo, la OMS declaró la pandemia de la COVID-19 (nombre oficial de la infección por SARS-CoV-2). Desde entonces y hasta finales de febrero de 2021, se han notificado más de 113 millones de casos en el mundo; en España, se han registrado más de 3 millones de casos y cerca de 70000 fallecidos por esta causa ${ }^{3}$.

La COVID-19 cursa generalmente con fiebre, malestar general y síntomas clínicos compatibles con una infección respiratoria aguda (tos seca, disnea). Otros síntomas que pueden presentarse son anosmia, ageusia, odinofagia, cefalea, mialgias y síntomas gastrointestinales. En los casos más graves, puede causar neumonía, síndrome respiratorio agudo grave, insuficiencia renal e, incluso, la muerte. Asociadas a la COVID-19 se han observado manifestaciones dermatológicas muy variadas, que se han clasificado en cinco grupos principales: lesiones acras, exantemas vesiculares, erupciones urticariales, exantemas maculopapulosos y lesiones livedoides/necróticas. Esta clínica puede ser el reflejo de distintas vías patogénicas con implicación variable de la infección vírica, del proceso inflamatorio, de las complicaciones vasculares o sistémicas de la enfermedad o, incluso, de los tratamientos administrados ${ }^{4,5}$.

El desarrollo de vacunas frente al SARS-CoV-2 ha sido un reto. Tradicionalmente, el desarrollo de las vacunas ha necesitado de 10 a 15 años, pero, en esta pandemia, el 1 marzo de 2020 arrancó el primer estudio de fase I sobre vacunas de la COVID-19 y, en poco más de nueve meses, el 11 de diciembre, la Administración de Alimentos y Medicamentos de los Estados Unidos (FDA, Food and Drug Administration) emitió la autorización de uso de emergencia para la primera vacuna (Comirnaty, BNT162b2 de BioNTech \& Pfizer) para la prevención de esta enfermedad en personas de 16 o más años de edad. Diez días después, la Agencia Europea de Medicamentos (EMA, European Medicines Agency) recomendó su autorización, y la Comisión Europea aprobó su comercialización condicional ese mismo día. Un año después del inicio del primer ensayo de vacunas frente a la COVID-19, hay tres vacunas disponibles en España y, en breve, se espera alguna más.

Superar las posibles dudas frente a estas vacunas supone un desafío importante para poder detener la propagación del virus y, para ello, es fundamental ofrecer información y educación de salud pública correcta, para que la aceptación de la vacuna por parte de la población no comprometa los objetivos que se desea alcanzar³.

\section{BIBLIOGRAFÍA}

1. Balaguer Perigüell E, Ballester Añón R. En el nombre de los niños: la Real Expedición Filantrópica de la Vacuna (18031806). Monografías de la AEP, n.o 2. Madrid: Asociación Española de Pediatría (AEP); 2003. Disponible en: https://www. aeped.es/documentos/en-nombre-los-ninos-real-expedicionfilantropica-vacuna-1803-180

2. Ministerio de Sanidad. Centro de Coordinación de Alertas y Emergencias Sanitarias. Actualización n.ํ 322. Enfermedad por el coronavirus (COVID-19). 01.03.2021. Disponible en: https://www.mscbs.gob.es/profesionales/saludPublica/ ccayes/alertasActual/nCov/documentos/Actualizacion_322 COVID-19.pdf

3. Grupo de Trabajo Técnico de Vacunación COVID-19, de la Ponencia de Programa y Registro de Vacunaciones. Actualización 3. Estrategia de vacunación frente a COVID-19 en España. 9 de febrero de 2021. Consejo Interterritorial. Sistema Nacional de Salud. Disponible en: https://www.mscbs.gob. es/profesionales/saludPublica/prevPromocion/vacunaciones/ covid19/docs/COVID-19_Actualizacion3_EstrategiaVacuna cion.pdf

4. Galván Casas C, Català A, Carretero Hernández G, Rodríguez-Jiménez $P$, Fernández-Nieto $D$, Rodríguez-Villa Lario $A$, et al. Classification of the cutaneous manifestations of COVID19: a rapid prospective nationwide consensus study in Spain with 375 cases. Br J Dermatol. 2020;183(1):71-7.

5. Carrascosa JM, Morillas V, Bielsa I, Munera-Campos M. Manifestaciones cutáneas en el contexto de la infección por SARSCoV-2 (COVID-19). Actas Dermosifiliogr. 2020;111(9):734-42. 